\title{
Reduced lung function is independently associated with increased risk of type 2 diabetes in Korean men
}

\author{
Chang-Hee Kwon ${ }^{1 \dagger}$, Eun-Jung Rhee ${ }^{2 \dagger}$, Jae-Uk Song ${ }^{3}$, Jung-Tae Kim ${ }^{4}$, Hyon Joo Kwag ${ }^{5}$ and Ki-Chul Sung ${ }^{6 *}$
}

\begin{abstract}
Background: Reduced lung function is associated with incident insulin resistance and diabetes. The aim of this study was to assess the relationship between lung function and incident type 2 diabetes in Korean men.

Methods: This study included 9,220 men (mean age: 41.4 years) without type 2 diabetes at baseline who were followed for five years. Subjects were divided into four groups according to baseline forced vital capacity (FVC) (\% predicted) and forced expiratory volume in one second ( $\left.\mathrm{FEV}_{1}\right)$ (\% predicted) quartiles. The incidence of type 2 diabetes at follow-up was compared according to FVC and $\mathrm{FEV}_{1}$ quartiles.

Results: The overall incidence of type 2 diabetes was 2.2\%. Reduced lung function was significantly associated with the incidence of type 2 diabetes after adjusting for age, BMI, education, smoking, exercise, alcohol, and HOMA-IR. Both FVC and FEV 1 were negatively associated with type 2 diabetes $(P<0.05)$. In non-obese subjects with $\mathrm{BMI}<25$, the lowest quartile of FVC and $\mathrm{FEV}_{1}$ had a significantly higher odds ratio for type 2 diabetes compared with the highest quartile after adjusting for age and BMI (2.15 [95\% Cl 1.02-4.57] and 2.19 [95\% Cl 1.09-4.42]).
\end{abstract}

Conclusions: Reduced lung function is independently associated with the incidence of type 2 diabetes in Korean men.

Keywords: Lung function, Type 2 diabetes mellitus, Retrospective study

\section{Background}

Obesity is a serious problem that causes various metabolic diseases [1,2]. Type 2 diabetes is a representative metabolic diseases that is caused by obesity, and recent survey presents rapidly increasing prevalence of diabetes in Koreans [3].

The association between obesity and respiratory dysfunction is as old as recorded history [4], and obstructive sleep apnea could be the link that associates obesity with reduced lung function [5]. In a very recent study by Fredheim et al. [6] showed direct associations of prediabetes and type 2 diabetes with obstructive sleep apnea in extremely obese subjects, suggesting possible link between sleep apnea, reduced lung function and glucose

\footnotetext{
* Correspondence: kcmd.sung@samsung.com

${ }^{\dagger}$ Equal contributors

${ }^{5}$ Department of Radiology, Kangbuk Samsung Hospital, Sungkyunkwan

University School of Medicine, Seoul, Korea

Full list of author information is available at the end of the article
}

intolerance. From the above algorithm, reduced lung function as measured by forced vital capacity (FVC) or forced expiratory volume in one second $\left(\mathrm{FEV}_{1}\right)$ could be suggested as the predictor for type 2 diabetes development [7-11]. These studies suggest that lung dysfunction may be associated with the development of type 2 diabetes. However, the causal direction between reduced lung function and diabetes, as well as the underlying mechanism to explain this association, remains unclear.

Although a number of Asian studies have also revealed a significant association between reduced lung function and insulin resistance, metabolic syndrome and type 2 diabetes [12-15], they were limited by their crosssectional nature. Here we investigated whether reduced lung function was a significant predictor of incident type 2 diabetes in Korean men by a five-year follow-up study. 


\section{Subjects and methods Subjects}

Study subjects were selected from a total of 10,965 men who visited Kangbuk Samsung Hospital Health Promotion Center for health examinations in both 2003 and 2008. The purpose of the medical health checkup program is to promote the health of the employees through regular health checkups and to enhance early detection of existing diseases, if any. Most of the examinees are the employees and family members of various industrial companies from all around the country. The costs of the medical examinations are largely paid for by their employers, and a considerable proportion of the examinees undergo examinations annually or biannually. We took advantage of this opportunity to conduct a follow-up study.

Among the potential study subjects, 1,745 individuals were excluded; 139 individuals had a history of type 2 diabetes, 237 individuals had fasting plasma glucose $\geq 7.0 \mathrm{mmol} / \mathrm{L}$ (126 mg/dl) in 2003 (baseline visit), 31 individuals did not have available $\mathrm{FEV}_{1}$ or FVC level measurements, and 1,338 individuals had no available data regarding education, alcohol, smoking or exercise. Finally, 9,220 men (mean age: 41.4 years, range: 24 to 82 years) who did not have type 2 diabetes in 2003 (baseline visit) were enrolled in the study and were followed up for five years. The study subjects were divided into quartiles according to the baseline percentage of predicted values (\% predicted) for $\mathrm{FEV}_{1}$ or FVC. Based on $\mathrm{FEV}_{1}$ (\% predicted), the resulting four categories were as follows: $\leq 94.6 \%$ in quartile $1,94.6-105.5 \%$ in quartile 2, 105.5 $119.9 \%$ in quartile 3 , and $>119.9 \%$ in quartile 4 . The subjects were similarly divided into quartiles based on FVC (\% predicted): $\leq 89.4 \%$ in quartile $1,89.4-98.6 \%$ in quartile 2 , $98.6-109.1 \%$ in quartile 3 , and $\geq 109.1 \%$ in quartile 4 . We then compared the incidence of type 2 diabetes according to different FVC (\% predicted) and $\mathrm{FEV}_{1}$ (\% predicted) groups after a follow-up survey.

Medical and medication history, smoking status (current, ex-, or non-smoker), alcohol consumption (g/day), regular exercise ( $\geq$ once per week), and education status were assessed using the same standard questionnaire in 2003 and 2008. Blood pressure (BP) was measured with a standard sphygmomanometer following at least five minutes of seated rest. Height and weight were estimated using automated instruments, with individuals wearing light clothing and no shoes. Body mass index (BMI) was calculated as body weight (kilograms) divided by height squared $\left(\right.$ meters $\left.^{2}\right)$.

The study protocol conformed to ethical guidelines of the 1975 Declaration of Helsinki, and accordingly the Kangbuk Samsung Hospital Human Research Committee approved it. The Kangbuk Samsung Hospital Institutional Review Board also approved this study and each participant gave their written informed consent.

\section{Measurements}

Morning blood samples were drawn from the antecubital vein after participants had fasted for at least 12 hours. Plasma glucose levels were determined using the hexokinase method (Advia 1650 AutoAnalyzer, Bayer Diagnostics, Leverkusen, Germany). Insulin concentrations were measured using immunoradiometric assays (RIABEAD II, Abbott, Tokyo, Japan), with intra- and inter-assay coefficients of variance of $1.2-1.9 \%$ and $1.4-3.3 \%$, respectively. Insulin resistance was estimated using the homeostasis model assessment of insulin resistance index (HOMA-IR), which is defined as fasting insulin $(\mu \mathrm{IU} / \mathrm{ml}) \mathrm{x}$ fasting glucose $(\mathrm{mmol} / \mathrm{L}) / 22.5$ [16]. Fasting total cholesterol (TC) and triglyceride (TG) levels were measured enzymatically using an automatic analyzer (Advia 1650 AutoAnalyzer, Bayer Diagnostics, Leverkusen, Germany). High density lipoprotein cholesterol (HDL-C) concentrations were measured using a selective inhibition technique. Levels of low density lipoprotein cholesterol (LDL-C) were determined through a homogeneous enzymatic calorimetric test. Type 2 diabetes was defined as fasting plasma glucose $\geq 7.0 \mathrm{mmol} / \mathrm{L}$ (126 mg/dL) based on 1997 American Diabetes Association criteria, current usage of diabetes medication, or positive response to the question, "Has a medical person ever told you that you had diabetes?" [17].

\section{Lung function assessment}

Spirometry was performed as recommended by the American Thoracic Society [18] using $\mathrm{V}_{\max } 22$ (SensorMedics, Yorba Linda, CA, USA). Absolute values of $\mathrm{FEV}_{1}$ and $\mathrm{FVC}$ were obtained, and the percentage predicted values (\% predicted) for $\mathrm{FEV}_{1}$ and FVC were calculated from the following equations obtained in a representative Korean population sample [19]:

$$
\begin{aligned}
\text { PredictedFVC }= & -4.8434-\left(0.00008633 \times \operatorname{age}^{2}[\text { years }]\right) \\
& +(0.05292 \times \text { height }[\mathrm{cm}]) \\
& +(0.01095 \times \text { weight }[\mathrm{kg}]) \\
\text { PredictedFEV }_{1}= & -3.4132-\left(0.0002484 \times \text { age }^{2}[\text { years }]\right) \\
& +(0.04578 \times \text { height }[\mathrm{cm}])
\end{aligned}
$$

The highest $\mathrm{FEV}_{1}$ and FVC values from three or more tests with acceptable curves were used for further analyses. The FVC (\% predicted) and $\mathrm{FEV}_{1}$ (\% predicted) were calculated by dividing the FVC (L) and $\mathrm{FEV}_{1}(\mathrm{~L})$ by the predicted FVC and $\mathrm{FEV}_{1}$, respectively.

The reliability of the spirometry is proved in the previously published report [15].

\section{Statistical analysis}

Data are expressed as the mean \pm standard deviation (SD) for continuous variables and as percentages for 
categorical variables. Serum TG concentration was logtransformed for analysis to correct skewed distributions, but the values in the tables are expressed as untransformed data for easy interpretation. Comparisons of baseline cardiovascular risk factors according to the presence/ absence of incident type 2 diabetes were made using Student's $t$-test for continuous variables or the chi-square test for categorical variables. Comparisons of baseline variables between the lowest and highest quartiles of $\mathrm{FEV}_{1}$ (\% predicted) or FVC (\% predicted) were made by Student's $t$ test or the chi-square test. Comparisons of type 2 diabetes development according to $\mathrm{FEV}_{1}$ (\% predicted) or FVC (\% predicted) quartiles were obtained from chi-square tests. Multivariable logistic regression analyses were conducted to assess the relationship between $\mathrm{FEV}_{1}$ (\% predicted) or FVC (predicted) quartiles and the risk of incident type 2 diabetes: model 1 was adjusted for age and BMI; model 2 was adjusted as in model 1 plus education, smoking, exercise, alcohol, and insulin; model 3 was adjusted as in model 1 plus education, smoking, exercise, alcohol, and HOMA-IR. The outcome in this study was type 2 diabetes at five years and all subjects had been followed for approximately five years. Therefore, our data for the analysis was complete (not censored) in terms of outcome. For this reason, data was analyzed by logistic regression instead of using a Cox regression model. All statistical analyses were performed using PASW for Windows, version 18.0 (SPSS Inc., Chicago, IL, USA). All statistical tests were two-tailed, and $P$-values $<0.05$ were considered statistically significant.

\section{Results}

The overall incidence of type 2 diabetes in the study population was $2.2 \%$ (207 of 9,220 men). According to the quartiles of FVC (\% predicted), the incidence of type 2 diabetes was $3.6 \%$ in the lowest quartile (quartile 1), $1.7 \%$ in the second (quartile 2), $2.3 \%$ in the third (quartile 3), and $1.3 \%$ in the highest quartile (quartile 4$)(\mathrm{P}<0.0001)$. Moreover, the difference in incidence of type 2 diabetes according to the quartile of $\mathrm{FEV}_{1}$ (\% predicted) was also significant [3.1\% in quartile $1,2.3 \%$ in quartile $2,1.9 \%$ in quartile 3 , and $1.7 \%$ in quartile $4(\mathrm{P}=0.005)]$. The overall incidence of type 2 diabetes in the study group was similar to that of the excluded subjects $[2.2 \%(207 / 9,220)$ vs. $2.0 \%$ $(35 / 1,745)$, respectively, $\mathrm{P}=0.438]$.

\section{Clinical characteristics of the subjects according to diabetes development at follow-up}

Baseline characteristics of the non-diabetes group and the diabetes group at follow-up are presented in Table 1. Individuals in the diabetes group were older and more likely to have higher mean $\mathrm{BP}$, heart rate (HR), BMI, TC, TG, glucose, insulin, and HOMA-IR, and lower HDL-C, $\mathrm{FEV}_{1}(\mathrm{~L})$, and FVC (L) values compared with those in the non-diabetes group. In addition, there were more subjects in the diabetes group who were obese, currently smoking, and who had a low-level of education (Table 1).

\section{Baseline characteristics according to quartiles of $\mathrm{FEV}_{\mathbf{1}}$ (\% predicted) and FVC (\% predicted)}

The baseline characteristics of the lowest and highest quartiles of $\mathrm{FEV}_{1}$ (\% predicted) and FVC (\% predicted) were compared (Table 2). In the lowest quartile (quartile 1) of $\mathrm{FEV}_{1}$ (\% predicted), TG, glucose and the percentage of current smokers were significantly higher compared to the highest quartile (quartile 4). However, age, $\mathrm{HR}$, BMI, HDL-C, insulin and alcohol consumption were significantly lower in the lowest quartile compared to the highest quartile. On the other hand, subjects in quartile 1 of FVC (\% predicted) were older, more likely to have higher BP, BMI, TG, glucose, insulin and HOMA-IR, and had lower HR and HDL-C compared to quartile 4.

\section{Analysis of future risk for incidence of type 2 diabetes after a five-year follow-up according to baseline lung function and obesity}

In age- and BMI-adjusted logistic regression analysis (model 1), the lowest quartiles of FVC (\% predicted) and $\mathrm{FEV}_{1}$ (\% predicted) had a higher odds ratio (OR) for the incidence of type 2 diabetes compared to the highest quartile reference category (OR [95\% confidence interval (CI)], 2.18[1.42-3.32] and 1.95[1.31-2.92], $\mathrm{P}<0.0001$ and $\mathrm{P}=0.001$, respectively) (Table 3 , Figure 1 ). The OR results from models 2 and 3 were attenuated, but were still significant in FVC (\% predicted) and $\mathrm{FEV}_{1}$ (\% predicted). Moreover, analysis with model 3 including age, BMI, education, smoking, exercise, alcohol, and HOMAIR revealed that the ORs in FVC (\% predicted) and $\mathrm{FEV}_{1}$ (\% predicted) quartile 1 were significantly higher compared with those in quartile 4 (OR [95\% CI], 1.90[1.232.93] and 1.66[1.10-2.50], $\mathrm{P}=0.004$ and $\mathrm{P}=0.019$, respectively).

We also conducted a sub-analysis of 5,417 non-obese subjects with BMI $<25$ (mean BMI: $22.7 \pm 1.6$, range: 16.1 to 24.9$)$ to evaluate the association between lung function and type 2 diabetes in the non-obese population. In the non-obese subjects with $\mathrm{BMI}<25$, quartile 1 of FVC (\% predicted) and $\mathrm{FEV}_{1}$ (\% predicted) had a significantly increased OR for type 2 diabetes compared to quartile 4 after adjusting for age and BMI (OR[95\% CI], 2.15[1.02-4.57] and 2.19[1.09-4.42], $\mathrm{P}=0.045$ and $\mathrm{P}=0.028$, respectively) (Table 4 ).

\section{Discussion}

The major findings of this study are 1) the subjects with reduced lung function as measured with FVC (\% 
Table 1 Baseline characteristics of the non-diabetic and diabetic groups at follow-up

\begin{tabular}{|c|c|c|c|}
\hline & $\begin{array}{c}\text { Non-diabetic } \\
\text { group }(n=9,013)\end{array}$ & $\begin{array}{c}\text { Diabetic } \\
\text { group }(n=207) \\
\end{array}$ & $P$ value \\
\hline Age (years) & $41.3 \pm 5.8$ & $42.6 \pm 5.6$ & 0.002 \\
\hline Systolic BP (mmHg) & $117.0 \pm 12.4$ & $122.6 \pm 14.7$ & $<0.0001$ \\
\hline Diastolic BP (mmHg) & $76.6 \pm 9.3$ & $80.3 \pm 10.6$ & $<0.0001$ \\
\hline $\mathrm{HR}(\mathrm{n} / \mathrm{min})$ & $65.6 \pm 8.8$ & $68.5 \pm 10.2$ & $<0.0001$ \\
\hline $\mathrm{BMI}\left(\mathrm{kg} / \mathrm{m}^{2}\right)$ & $24.4 \pm 2.6$ & $26.7 \pm 3.3$ & $<0.0001$ \\
\hline $\mathrm{TC}(\mathrm{mmol} / \mathrm{L})$ & $5.42 \pm 0.90$ & $5.59 \pm 0.94$ & 0.007 \\
\hline $\mathrm{TG}(\mathrm{mmol} / \mathrm{L})$ & $1.73 \pm 0.98$ & $2.36 \pm 1.64$ & $<0.0001$ \\
\hline $\mathrm{HDL}-\mathrm{C}(\mathrm{mmol} / \mathrm{L})$ & $1.35 \pm 0.26$ & $1.28 \pm 0.23$ & $<0.0001$ \\
\hline LDL-C (mmol/L) & $3.16 \pm 0.75$ & $3.25 \pm 0.73$ & 0.072 \\
\hline Glucose (mmol/L) & $5.20 \pm 0.45$ & $6.00 \pm 0.50$ & $<0.0001$ \\
\hline Insulin (pmol/L) & $50.58 \pm 19.36$ & $67.86 \pm 31.88$ & $<0.0001$ \\
\hline HOMA-IR & $1.69 \pm 0.69$ & $2.61 \pm 1.24$ & $<0.0001$ \\
\hline $\mathrm{FEV}_{1}(\mathrm{~L})$ & $4.32 \pm 0.81$ & $4.13 \pm 0.84$ & 0.001 \\
\hline $\mathrm{FVC}(\mathrm{L})$ & $4.88 \pm 0.90$ & $4.71 \pm 0.86$ & 0.010 \\
\hline $\mathrm{FEV}_{1}(\%)$ & $108.0 \pm 18.7$ & $103.5 \pm 19.1$ & 0.001 \\
\hline FVC (\%) & $100.2 \pm 17.1$ & $95.2 \pm 15.3$ & $<0.0001$ \\
\hline Alcohol (g/day) & $14.3 \pm 16.1$ & $16.6 \pm 19.6$ & 0.097 \\
\hline \multicolumn{4}{|l|}{ Weight class, n (\%) } \\
\hline $\mathrm{BMI}<25$ & $5,353(59.4)$ & $64(30.9)$ & $<0.0001$ \\
\hline $\mathrm{BMI} \geq 25$ & $3,659(40.6)$ & $143(69.1)$ & \\
\hline \multicolumn{4}{|l|}{$\begin{array}{l}\text { Smoking status, } \\
\mathrm{n}(\%)\end{array}$} \\
\hline Non-smoker & $2,858(31.7)$ & $50(24.2)$ & 0.029 \\
\hline Ex-smoker & $2,418(26.8)$ & $54(26.1)$ & \\
\hline Current-smoker & $3,736(41.5)$ & $103(49.8)$ & \\
\hline \multicolumn{4}{|l|}{ Education status, n (\%) } \\
\hline$\leq 12$ years & $1,689(18.7)$ & 49 (23.7) & 0.004 \\
\hline$\leq 14$ years & $706(7.8)$ & $26(12.6)$ & \\
\hline$\geq 16$ years & 6,618 (73.4) & $132(63.8)$ & \\
\hline \multicolumn{4}{|l|}{$\begin{array}{l}\text { Regular exercise, } \\
\text { n (\%) }\end{array}$} \\
\hline None & $2,221(24.6)$ & $47(22.7)$ & 0.44 \\
\hline$<1$ time/week & $3,523(39.1)$ & $90(43.5)$ & \\
\hline$\geq 1$ time/week & $3,269(36.2)$ & 70 (33.8) & \\
\hline \multicolumn{4}{|l|}{ FVC (\%) quartiles, n (\%) } \\
\hline Q $1(\leq 89.4)$ & $2,221(24.6)$ & $84(40.6)$ & $<0.0001$ \\
\hline Q 2 (89.4-98.6) & $2,265(25.1)$ & $40(19.3)$ & \\
\hline Q 3 (98.6-109.1) & $2,253(25.0)$ & $52(25.1)$ & \\
\hline Q 4 (>109.1) & $2,274(25.2)$ & $31(15.0)$ & \\
\hline \multicolumn{4}{|l|}{$\begin{array}{l}\mathrm{FEV}_{1}(\%) \text { quartiles, } \\
\mathrm{n}(\%)\end{array}$} \\
\hline Q 1 ( $\leq 94.6)$ & $2,233(24.8)$ & $72(34.8)$ & 0.005 \\
\hline Q 2 (94.6-105.5) & $2,252(25.0)$ & $53(25.6)$ & \\
\hline
\end{tabular}

Table 1 Baseline characteristics of the non-diabetic and diabetic groups at follow-up (Continued)

$\begin{array}{rll}\text { Q } 3(105.5-119.9) & 2,262(25.1) & 43(20.8) \\ \text { Q } 4(>119.9) & 2,266(25.1) & 39(18.8)\end{array}$

Values are mean \pm SD for continuous variables and number (percentages) for categorical variables. $\mathrm{P}$ values for continuous variables were obtained from the Student's $t$ test. $\mathrm{P}$ values for categorical variables were obtained from Chisquare tests. TG was expressed as raw data but was applied for statistical analysis after natural logarithmic transformation.

$\mathrm{BP}$, blood pressure; $\mathrm{HR}$, heart rate; $\mathrm{BMI}$, body mass index; TC, total cholesterol; TG, triglyceride; $\mathrm{HDL}-\mathrm{C}$, high-density lipoprotein cholesterol; LDL-C, low density lipoprotein cholesterol; HOMA-IR, homeostasis model assessment - insulin resistance; FEV1, forced expiratory volume in one second; FVC, forced vital capacity; $\mathrm{Q}$, quartile.

predicted) and $\mathrm{FEV}_{1}$ (\% predicted) had higher incidence of type 2 diabetes, independent of other confounding factors including age, BMI, education, smoking, exercise, alcohol and HOMA-IR; and 2) in non-obese subjects with BMI $<25$, decreased FVC (\% predicted) and $\mathrm{FEV}_{1}$ (\% predicted) were also inversely and significantly correlated with the incidence of type 2 diabetes. Our findings are generally consistent with previous studies that reported a significant association between reduced lung function and type 2 diabetes [8-10,20,21].

Previous studies have reported that the risk of being relatively insulin resistant, as measured by HOMA-IR, significantly increased as lung function decreased [7,9,21]. In the Normative Aging Study, 1,050 non-diabetic male subjects were followed over 20 years. Lower FVC, $\mathrm{FEV}_{1}$, and maximal mid-expiratory flow rate at baseline were significantly associated with risk of hyperinsulinemia and estimated insulin resistance [7]. Some epidemiologic and clinical studies have found that decreased lung function is associated with type 2 diabetes, independent of obesity [8-10,21-23]. In Asia, a number of studies have reported relationships between lung function and type 2 diabetes, insulin resistance and metabolic syndrome (MS) [12$15,24,25]$. Although studies were limited by their crosssectional design or small cohorts, they suggested that FVC and $\mathrm{FEV}_{1}$ could be predictive markers of incident type 2 diabetes or MS in Asian populations. Recently, The Strong Heart Study reported that reduced lung function is independently associated with diabetes, and impaired lung function presents before the development of diabetes in American Indians [23].

Type 2 diabetes is associated with insulin resistance and glucose tolerance, which could originate from visceral obesity [26]. Yeh et al. found that abdominal obesity is a significant factor affecting type 2 diabetes, MS, and pulmonary function test results [23]. Another study by Jung et al. [27] reported that nonalcoholic fatty liver disease, a well-known marker for insulin resistance and MS, was associated with reduced pulmonary function. In our study, subjects in the diabetes group had a significantly higher BMI and lower FVC and $\mathrm{FEV}_{1}$ (L) at 
Table 2 Baseline characteristics according to quartiles of FEV (\% predicted) and FVC (\% predicted)

\begin{tabular}{|c|c|c|c|c|c|c|}
\hline & \multicolumn{2}{|c|}{$\mathrm{FEV}_{1}(\%)$} & \multicolumn{4}{|c|}{ FVC (\%) } \\
\hline & $\begin{array}{c}\text { Quartile } 1 \\
(\leq 94.6)\end{array}$ & $\begin{array}{c}\text { Quartile } 4 \\
(>119.9)\end{array}$ & $P$ value & $\begin{array}{c}\text { Quartile1 } \\
(\leq 89.4)\end{array}$ & $\begin{array}{c}\text { Quartile } 4 \\
(>109.1)\end{array}$ & $P$ value \\
\hline$n$ & 2305 & 2305 & & 2305 & 2305 & \\
\hline Age (years) & $40.8 \pm 5.7$ & $41.9 \pm 6.1$ & $<0.0001$ & $42.2 \pm 6.5$ & $40.9 \pm 5.4$ & $<0.0001$ \\
\hline Systolic BP (mmHg) & $117.5 \pm 12.8$ & $117.5 \pm 12.6$ & 0.989 & $118.0 \pm 13.1$ & $117.0 \pm 12.2$ & 0.008 \\
\hline Diastolic BP (mmHg) & $77.2 \pm 9.7$ & $76.6 \pm 9.3$ & 0.039 & $77.5 \pm 9.7$ & $76.4 \pm 9.1$ & $<0.0001$ \\
\hline $\mathrm{HR}(\mathrm{n} / \mathrm{min})$ & $65.1 \pm 8.8$ & $66.7 \pm 9.2$ & $<0.0001$ & $65.5 \pm 8.8$ & $66.3 \pm 9.2$ & 0.002 \\
\hline $\mathrm{BMI}\left(\mathrm{kg} / \mathrm{m}^{2}\right)$ & $24.5 \pm 2.8$ & $24.7 \pm 2.5$ & 0.011 & $24.8 \pm 2.8$ & $24.3 \pm 2.4$ & $<0.0001$ \\
\hline $\mathrm{TC}(\mathrm{mmol} / \mathrm{L})$ & $5.43 \pm 0.93$ & $5.48 \pm 0.91$ & 0.073 & $5.46 \pm 0.92$ & $5.44 \pm 0.92$ & 0.415 \\
\hline TG $(\mathrm{mmol} / \mathrm{L})$ & $1.84 \pm 1.14$ & $1.72 \pm 0.95$ & $<0.0001$ & $1.84 \pm 1.14$ & $1.68 \pm 0.97$ & $<0.0001$ \\
\hline $\mathrm{HDL}-\mathrm{C}(\mathrm{mmol} / \mathrm{L})$ & $1.32 \pm 0.25$ & $1.38 \pm 0.26$ & $<0.0001$ & $1.33 \pm 0.25$ & $1.38 \pm 0.26$ & $<0.0001$ \\
\hline LDL-C (mmol/L) & $3.17 \pm 0.76$ & $3.19 \pm 0.76$ & 0.356 & $3.18 \pm 0.74$ & $3.17 \pm 0.76$ & 0.613 \\
\hline Glucose (mmol/L) & $5.30 \pm 0.46$ & $5.13 \pm 0.47$ & $<0.0001$ & $5.30 \pm 0.47$ & $5.12 \pm 0.47$ & $<0.0001$ \\
\hline Insulin (pmol/L) & $51.08 \pm 20.63$ & $52.40 \pm 19.61$ & 0.026 & $52.65 \pm 21.16$ & $50.94 \pm 19.43$ & 0.004 \\
\hline HOMA-IR & $1.74 \pm 0.77$ & $1.73 \pm 0.70$ & 0.437 & $1.80 \pm 0.79$ & $1.68 \pm 0.69$ & $<0.0001$ \\
\hline $\mathrm{FEV}_{1}(\mathrm{~L})$ & $3.46 \pm 0.39$ & $5.33 \pm 0.59$ & $<0.0001$ & $3.57 \pm 0.46$ & $5.25 \pm 0.67$ & $<0.0001$ \\
\hline FVC (L) & $4.20 \pm 0.96$ & $5.77 \pm 0.68$ & $<0.0001$ & $4.02 \pm 0.41$ & $5.88 \pm 0.97$ & $<0.0001$ \\
\hline Alcohol (g/day) & $13.4 \pm 16.0$ & $15.5 \pm 16.6$ & $<0.0001$ & $14.3 \pm 16.4$ & $15.0 \pm 16.6$ & 0.166 \\
\hline Current smoker, n (\%) & $1053(45.7)$ & $906(39.3)$ & $<0.0001$ & $972(42.2)$ & $935(40.6)$ & 0.393 \\
\hline
\end{tabular}

Values are mean \pm SD for continuous variables. P values for continuous variables were obtained from the Student's $t$ test. TG was expressed as raw data but was applied for statistical analysis after natural logarithmic transformation.

FEV1, forced expiratory volume in one second; FVC, forced vital capacity; BP, blood pressure; HR, heart rate; BMI, body mass index; TC, total cholesterol; TG,

triglyceride; HDL-C, high-density lipoprotein cholesterol; LDL-C, low density lipoprotein cholesterol; HOMA-IR, homeostasis model assessment - insulin resistance.

baseline compared to those in the non-diabetes group. In addition, ventilatory function is partially determined by respiratory muscle strength, which may be compromised in obese subjects [28].
The association between diminished lung function and type 2 diabetes may be explained according to a common inflammatory process [29]. Obesity and metabolic syndrome are associated with elevated systemic inflammatory

Table 3 Multivariable logistic regression analysis for the association between lung function and incident type 2 diabetes during a five-year follow-up

\begin{tabular}{|c|c|c|c|c|c|c|c|}
\hline & \multirow{2}{*}{$\begin{array}{c}\text { Type } 2 \text { diabetes } \\
\text { n (\%) }\end{array}$} & \multicolumn{2}{|c|}{ Model 1} & \multicolumn{2}{|c|}{ Model 2} & \multicolumn{2}{|c|}{ Model 3} \\
\hline & & OR[95\% Cl] & $P$ & OR[95\% Cl] & $P$ & OR[95\% CI] & $P$ \\
\hline \multicolumn{8}{|l|}{ FVC } \\
\hline Q 1 & $84(3.6)$ & $2.18[1.42-3.32]$ & $<0.0001$ & $2.00[1.30-3.07]$ & 0.002 & $1.84[1.19-2.84]$ & 0.006 \\
\hline Q 2 & $40(1.7)$ & $1.18[0.73-1.91]$ & 0.487 & $1.16[0.72-1.87]$ & 0.548 & $1.11[0.69-1.80]$ & 0.665 \\
\hline Q 3 & $52(2.3)$ & $1.67[1.06-2.62]$ & 0.026 & $1.64[1.04-2.59]$ & 0.032 & $1.66[1.05-2.62]$ & 0.030 \\
\hline Q 4 & $31(1.3)$ & 1 & & 1 & & 1 & \\
\hline$P$ value & $<0.0001^{*}$ & & & & & & \\
\hline \multicolumn{8}{|l|}{$\mathrm{FEV}_{1}$} \\
\hline Q 1 & $72(3.1)$ & $1.95[1.31-2.92]$ & 0.001 & $1.78[1.18-2.67]$ & 0.006 & $1.58[1.04-2.39]$ & 0.030 \\
\hline Q 2 & $53(2.3)$ & $1.59[1.04-2.43]$ & 0.032 & $1.54[1.01-2.36]$ & 0.047 & $1.46[0.95-2.25]$ & 0.082 \\
\hline Q 3 & $43(1.9)$ & $1.20[0.77-1.86]$ & 0.428 & $1.14[0.73-1.79]$ & 0.555 & $1.08[0.69-1.70]$ & 0.734 \\
\hline Q 4 & $39(1.7)$ & 1 & & 1 & & 1 & \\
\hline$P$ value & $0.005^{*}$ & & & & & & \\
\hline
\end{tabular}

${ }^{*} P$ value was obtained from Chi-square tests for the comparisons of the incident diabetes among quartiles of FVC (\% predicted) and FEV $(\%$ predicted). Model 1 was adjusted for age and BMI.

Model 2 was adjusted as in model 1 plus education, smoking, exercise, alcohol and insulin.

Model 3 was adjusted as in model 1 plus education, smoking, exercise, alcohol, HOMA-IR, TC, TG, and HDL-C.

FEV1, forced expiratory volume in one second; FVC, forced vital capacity; OR, odds ratio; Cl, confidence interval; BMI, body mass index; HOMA-IR, homeostasis model assessment - insulin resistance; TC, total cholesterol; TG, triglyceride; HDL-C, high-density lipoprotein cholesterol. 


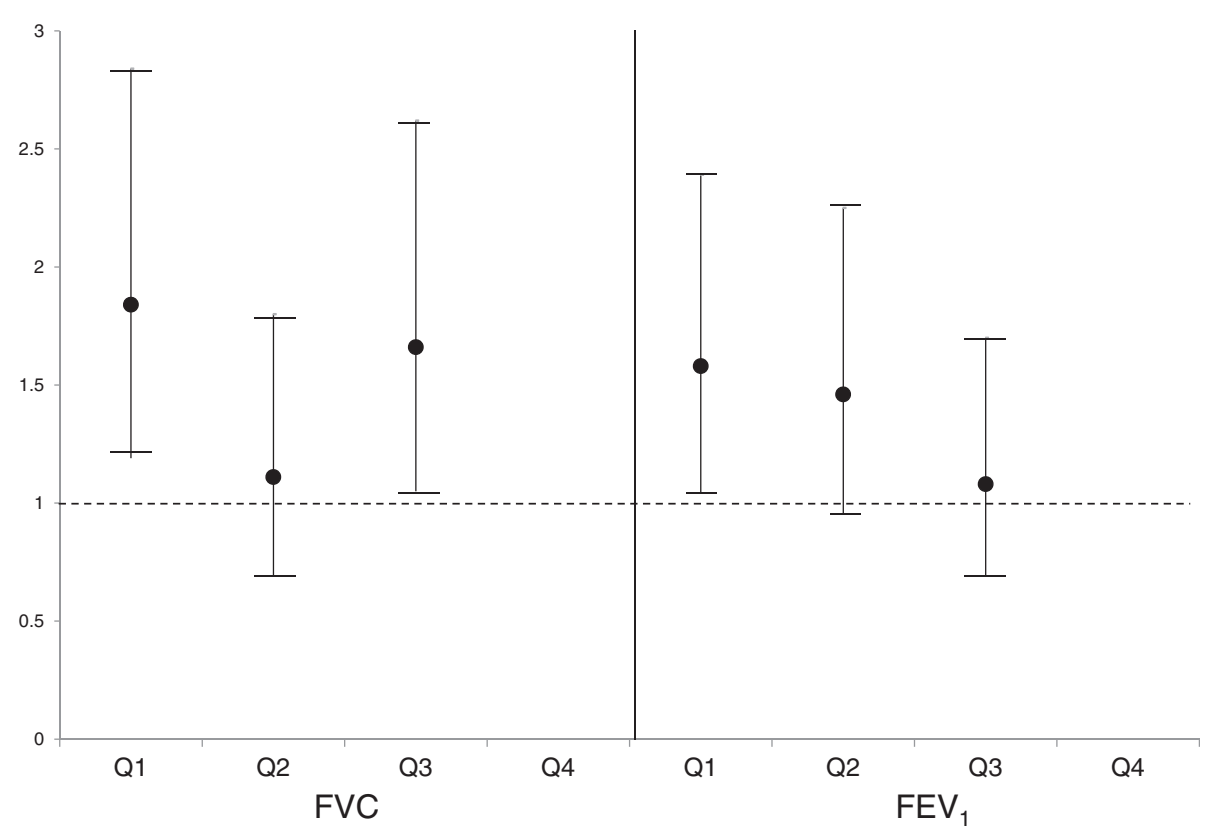

Figure 1 Odds ratio for the development of type 2 diabetes according to quartiles of baseline lung function during a five-year followup. FVC, forced vital capacity (\% predicted); FEV1, forced expiratory volume in one second (\% predicted).

markers and adipocytokines [30]. Alternatively, the induction of increased oxidative activity, intracellular NF-kB and inflammatory mediators could also result in chronic hyperglycemia and an increase in collagen molecule synthesis and cross-linking via the acceleration of advanced glycation end-products, ultimately negatively influencing lung function [31]. Moreover, previous studies have indicated that proinflammatory cytokines such as $\mathrm{C}$-reactive protein (CRP), fibrinogen and IL-6 may play a role in the pathogenesis of type 2 diabetes $[10,13,15,23]$, although a recent study showed no association of glucose control with hs-CRP [32]. However, we could not address the association between

Table 4 Multivariable logistic regression analysis for the association between lung function and incident type 2 diabetes in non-obese subjects (BMI $<25)$ during a five-year follow-up

\begin{tabular}{|c|c|c|c|c|c|c|c|}
\hline \multirow[b]{2}{*}{ FVC } & \multirow{2}{*}{$\begin{array}{c}\text { Type } 2 \text { diabetes } \\
\text { n (\%) }\end{array}$} & \multicolumn{2}{|c|}{ Model 1} & \multicolumn{2}{|c|}{ Model 2} & \multicolumn{2}{|c|}{ Model 3} \\
\hline & & OR[95\% Cl] & $P$ & OR[95\% Cl] & $P$ & OR[95\% Cl] & $P$ \\
\hline Q 1 & $23(1.7)$ & $2.15[1.02-4.57]$ & 0.045 & $2.06[0.97-4.38]$ & 0.061 & $1.93[0.90-4.12]$ & 0.091 \\
\hline Q 2 & $16(1.2)$ & $1.60[0.72-3.54]$ & 0.247 & $1.55[0.70-3.45]$ & 0.279 & $1.47[0.66-3.28]$ & 0.346 \\
\hline Q 3 & $15(1.1)$ & $1.50[0.67-3.36]$ & 0.322 & $1.53[0.68-3.42]$ & 0.305 & $1.51[0.67-3.41]$ & 0.317 \\
\hline Q 4 & $10(0.7)$ & 1 & & 1 & & 1 & \\
\hline$P$ value & $0.142^{*}$ & & & & & & \\
\hline \multicolumn{8}{|l|}{$\mathrm{FEV}_{1}$} \\
\hline Q 1 & $24(1.8)$ & $2.19[1.09-4.42]$ & 0.028 & $2.06[1.02-4.17]$ & 0.044 & $1.87[0.92-3.80]$ & 0.084 \\
\hline Q 2 & $14(1.0)$ & $1.30[0.60-2.83]$ & 0.508 & $1.25[0.57-2.72]$ & 0.581 & $1.17[0.53-2.57]$ & 0.694 \\
\hline Q 3 & $14(1.0)$ & $1.23[0.56-2.66]$ & 0.608 & $1.23[0.56-2.68]$ & 0.602 & $1.19[0.54-2.60]$ & 0.665 \\
\hline Q 4 & $12(0.9)$ & 1 & & 1 & & 1 & \\
\hline$P$ value & $0.135^{*}$ & & & & & & \\
\hline
\end{tabular}

${ }^{*} P$ value was obtained from Chi-square tests for the comparison of incident diabetes among quartiles of FVC (\% predicted) and FEV ${ }_{1}$ (\% predicted). Model 1 was adjusted for age and BMI.

Model 2 was adjusted as in model 1 plus education, smoking, exercise, alcohol and insulin.

Model 3 was adjusted as in model 1 plus education, smoking, exercise, alcohol, HOMA-IR, TC, TG, and HDL-C.

FEV1, forced expiratory volume in one second; FVC, forced vital capacity; OR, odds ratio; $\mathrm{Cl}$, confidence interval; BMI, body mass index; HOMA-IR, homeostasis model assessment - insulin resistance; TC, total cholesterol; TG, triglyceride; HDL-C, high-density lipoprotein cholesterol. 
inflammation and type 2 diabetes because most study subjects did not have available measurements of inflammatory markers such as CRP and IL-6.

\section{Limitations}

We note that our study had some limitations. First, there is the possibility of selection bias because most participants were residents of an urban community, all subjects were of Korean descent, from one university hospital, and there were no women in this study. Therefore, the results of this study cannot be generalized to the worldwide population. Second, incident type 2 diabetes was defined based only on fasting glucose level or a self-reported medical history of type 2 diabetes, and no oral glucose tolerance tests were performed. Thus, the incidence of type 2 diabetes may have been underestimated in this study. Third, risk of diabetes may have been influenced by early life style factors which was not investigated in this study. Therefore, future studies including birth cohort analysis are needed to clarify the cause-effect link between reduced lung function and risk of developing diabetes. Finally, our data consisted of only baseline and five-year follow-up time points. The outcome was considered the presence of type 2 diabetes at five years. Thus, logistic regression was used for analysis instead of a Cox regression model. However, our study had the advantage of including a relatively large total number of subjects over a relatively long follow-up period.

\section{Conclusions}

In conclusion, decreased FVC (\% predicted) and $\mathrm{FEV}_{1}(\%$ predicted) were significantly associated with the incidence of type 2 diabetes in Korean men. This result suggests that reduced lung function as measured by $\mathrm{FVC}$ and $\mathrm{FEV}_{1}$ might precede the development of type 2 diabetes. Further prospective studies will be required to confirm the association between reduced lung function and diabetes in Asian populations.

\section{Competing interests}

The authors declare that they have no competing interests.

\section{Acknowledgments}

We acknowledge the efforts of the health screening group at Kangbuk Samsung Hospital, Korea. This study was partially supported by the Samsung Biomedical Research Institute Grant SBRI C-B1-114-1.

\footnotetext{
Author details

'Department of Cardiology, Asan Medical Center, University of Ulsan College of Medicine, Seoul, South Korea. ${ }^{2}$ Department of Internal Medicine, Division of Endocrinology and Metabolism, Kangbuk Samsung Hospital, Sungkyunkwan University School of Medicine, Seoul, South Korea. ${ }^{3}$ Department of Internal Medicine, Division of Pulmonary and Critical Care Medicine, Kangbuk Samsung Hospital, Sungkyunkwan University School of Medicine, Seoul, South Korea. ${ }^{4}$ Department of Thoracic and Cardiovascular Surgery, Kangbuk Samsung Hospital, Sungkyunkwan University School of Medicine, Seoul, South Korea. ${ }^{5}$ Department of Radiology, Kangbuk Samsung Hospital, Sungkyunkwan University School of Medicine, Seoul, Korea. ${ }^{6}$ Division of Cardiology, Department of Internal Medicine, Kangbuk Samsung
}

Hospital, Sungkyunkwan University School of Medicine, 108 Pyung-dong, Jongno-Ku, Seoul110-746, South Korea.

\section{Authors' contributions}

CK and ER analyzed the data, drafted the manuscript and revised the manuscript. JS and JK commented on the revision of the manuscript. KS designed the study, collected and analyzed the data. All authors have given their final approval for publication of this version of the manuscript.

Received: 31 January 2012 Accepted: 2 April 2012

Published: 24 April 2012

\section{References}

1. Carobbio S, Rodriguez-Cuenca S, Vidal-Puig A: Origins of metabolic complications in obesity: ectopic fat accumulation. The importance of the qualitative aspect of lipotoxicity. Curr Opin Clin Nutr Metab Care 2011, 14:520-526.

2. Lee HT, Shin J, Lim YH, Kim BK, Kim YT, Lee JU, et al: The relationship between coronary artery calcification and bone mineral density in patients according to their metabolic syndrome status. Korean Circ J 2011, 41:76-82.

3. Kim DJ: The epidemiology of diabetes in Korea. Diabetes Metab J 2011, 35:303-308.

4. Littleton SW: Impact of obesity on respiratory function. Respirology 2012, 17:43-49.

5. Sharma B, Feinsilver S, Owens RL, Malhotra A, McSharry D, Karbowitz S: Obstructive airway disease and obstructive sleep apnea: effect of pulmonary function. Lung 2011, 189:37-41.

6. Fredheim JM, Rollheim J, Omland T, Hofsø D, Røislien J, Vegsgaard K, et al: Type 2 diabetes and pre-diabetes are associated with obstructive sleep apnea in extremely obese subjects: a cross-sectional study. Cardiovasc Diabetol 2011, 10:84

7. Lazarus R, Sparrow D, Weiss ST: Baseline ventilatory function predicts the development of higher levels of fasting insulin and fasting insulin resistance index: the normative aging study. Eur Respir J 1998, 12:641645.

8. Ford ES, Mannino DM: Prospective association between lung function and the incidence of diabetes: findings from the national health and nutrition examination survey epidemiologic follow-up study. Diabetes Care 2004, 27:2966-2970.

9. Yeh HC, Punjabi NM, Wang NY, Pankow JS, Duncan BB, Brancati FL: Vital capacity as a predictor of incident type 2 diabetes: the atherosclerosis risk in communities study. Diabetes Care 2005, 28:1472-1479.

10. Wannamethee SG, Shaper AG, Rumley A, Sattar N, Whincup PH, Thomas $M C$, et al: Lung function and risk of type 2 diabetes and fatal and nonfatal major coronary heart disease events: possible associations with inflammation. Diabetes Care 2010, 33:1990-1996.

11. Klein OL, Meltzer D, Carnethon M, Krishnan JA: Type II diabetes mellitus is associated with decreased measures of lung function in a clinical setting. Respir Med 2011, 105:1095-1098.

12. Oda $E$, Kawai $R$ : A cross-sectional relationship between vital capacity and metabolic syndrome and between vital capacity and diabetes in a sample japanese population. Environ Health Prev Med 2009, 14:284-291.

13. Oda E, Kawai R: A cross-sectional relationship between vital capacity and diabetes in Japanese men. Diabetes Res Clin Pract 2009, 85:111-116.

14. Kim SK, Hur KY, Choi YH, Kim SW, Chung JH, Kim HK, Lee MK, Min YK, Kim KW, Kim JH: The relationship between lung function and metabolic syndrome in obese and non-obese Korean adult males. Korean Diabetes $J$ 2010, 34:253-260.

15. Lim SY, Rhee EJ, Sung KC: Metabolic syndrome, insulin resistance and systemic inflammation as risk factors for reduced lung function in Korean nonsmoking males. J Korean Med Sci 2010, 25:1480-1486.

16. Quon MJ: Limitations of the fasting glucose to insulin ratio as an index of insulin sensitivity. J Clin Endocrinol Metab 2001, 86:4615-4617.

17. American Diabetes Association: Standards of medical care in diabetes2010. Diabetes Care 2010, 33:S11-S61.

18. Standardization of spirometry, 1994 update. American thoracic society. Am J Respir Crit Care Med 1995, 152:1107-1136.

19. Choi JK, Paek D, Lee JO: Normal predictive values of spirometry in korean population. Tuberc Respir Dis 2005, 58:230-242. 
20. Engstrom $G$, Janzon L: Risk of developing diabetes is inversely related to lung function: a population-based cohort study. Diabet Med 2002, 19:167-170

21. Engstrom G, Hedblad B, Nilsson P, Wollmer P, Berglund G, Janzon L: Lung function, insulin resistance and incidence of cardiovascular disease: a longitudinal cohort study. J Int Med 2003, 253:574-581.

22. Eriksson KF, Lindgarde F: Poor physical fitness, and impaired early insulin response but late hyperinsulinaemia, as predictors of niddm in middleaged swedish men. Diabetologia 1996, 39:573-579.

23. Yeh F, Dixon AE, Marion S, Schaefer C, Zhang Y, Best LG, et al: Obesity in adults is associated with reduced lung function in metabolic syndrome and diabetes: the strong heart study. Diabetes Care 2011, 34:2306-2313.

24. Hsiao FC, Wu CZ, Su SC, Sun MT, Hsieh CH, Hung YJ, et al: Baseline forced expiratory volume in the first second as an independent predictor of development of the metabolic syndrome. Metabolism 2010, 59:848-853.

25. Paek YJ, Jung KS, Hwang YI, Lee KS, Lee DR, Lee JU: Association between low pulmonary function and metabolic risk factors in Korean adults: the Korean national health and nutrition survey. Metabolism 2010, 59:1300-1306.

26. Reaven GM: The metabolic syndrome: requiescat in pace. Clin Chem 2005, 51:931-938.

27. Jung DH, Shim JY, Lee HR, Moon BS, Park BJ, Lee YJ: The relationship between nonalcoholic fatty liver disease and pulmonary function. Intern Med J 2011, in press

28. Chlif M, Keochkerian D, Mourlhon C, Choquet D, Ahmaidi S: Noninvasive assessment of the tension-time index of inspiratory muscles at rest in obese male subjects. Int J Obes (Lond) 2005, 29:1478-1483.

29. Hsia CC, Raskin P: Lung involvement in diabetes: does it matter? Diabetes Care 2008, 31:828-829

30. Park CS, Ihm SH, Park HJ, Shin WS, Kim PJ, Chang K, et al: Relationship between plasma adiponectin, retinol-binding protein 4 and uric Acid in hypertensive patients with metabolic syndrome. Korean Circ J 2011, 41:198-202

31. Tiengo A, Fadini GP, Avogaro A: The metabolic syndrome, diabetes and lung dysfunction. Diabet Met 2008, 34:447-454.

32. Martins RA, Jones JG, Cumming SP, Coelho E, Silva MJ, Teixeira AM, et al: Glycated hemoglobin and associated risk factors in older adults. Cardiovasc Diabetol 2012, 11:13.

doi:10.1186/1475-2840-11-38

Cite this article as: Kwon et al:: Reduced lung function is independently associated with increased risk of type 2 diabetes in Korean men.

Cardiovascular Diabetology 2012 11:38.

\section{Submit your next manuscript to BioMed Central and take full advantage of:}

- Convenient online submission

- Thorough peer review

- No space constraints or color figure charges

- Immediate publication on acceptance

- Inclusion in PubMed, CAS, Scopus and Google Scholar

- Research which is freely available for redistribution 